\title{
PELATIHAN MERANGKAI KOMPONEN RANGKAIAN LISTRIK DENGAN METODE "DEBU" (DEMONSTRASI, BAHAS, DAN UNJUK KERJA) BAGI GURU FISIKA DI DESA AIK DAREQ, KECAMATAN BATUKLIANG, LOMBOK TENGAH TAHUN 2019
}

\author{
Islahudin $^{1^{*}}$, Johri Sabaryati ${ }^{2}$, Zulkarnain ${ }^{3}$, Siti Khaerani ${ }^{4}$, Haerul Pathoni ${ }^{5}$, Kemal Idris ${ }^{6}$ \\ ${ }^{1 *}$ Dosen Fisika (Pendidikan Fisika, Universitas Muhammadiyah Mataram) \\ ${ }^{2}$ Dosen Fisika (Pendidikan Fisika, Universitas Muhammadiyah Mataram) \\ ${ }^{3}$ Dosen Fisika (Pendidikan Fisika, Universitas Muhammadiyah Mataram) \\ ${ }^{4}$ Guru Fisika (MA NW Darussalimin, Sengkol, Batukliang, Lombok Tengah) \\ ${ }^{5}$ Dosen Fisika (Pendidikan Fisika, Universitas Jambi) \\ ${ }^{6}$ Mahasiswa (Pendidikan Fisika, Universitas Muhammadiyah Mataram) \\ Corresponding author : \\ E-mail : (islahudin.ntb@gmail.com)
}

Diterima 9 Mei 2019, Disetujui 15 Mei 2019

\begin{abstract}
ABSTRAK
Pengabdian ini tentang pelatihan merangkai komponen rangkaian listrik dengan metode " $D E B U$ " (Demonstrasi, Bahas, dan Unjuk Kerja) bagi guru fisika di Desa Aik Dareq, Kecamatan Batukliang, Lombok Tengah Tahun 2019. Tujuan yang ingin dicapai dalam kegiatan ini adalah 1) meningkatkan kemampuan guru fisika merangkai sumber tegangan listrik berupa power supply untuk mengoperasikan rangkaian listrik yang sudah jadi maupun untuk memeriksa komponen listrik, 2) meningkatkan kemampuan guru fisika dalam melakukan pengukuran menggunakan alat-alat ukur listrik khususnya menggunakan multimeter baik pada listrik searah (DC) dan listrik bolak balik (AC). Pelatihan ini dilaksanakan di Laboratorium IPA Madrasah Aliyah Darussalimin NW Desa Sengkol, Kecamatan Batukliang, Lombok Tengah. Sasaran kegiatan ini antara lain 1) guru fisika Madrasah Aliyah di Desa Aik Dareq, Kecamatan Batukliang, 2) guru fisika Madrasah Tsanawiyah di Desa Aik Dareq, Kecamatan Batukliang. Adapun metode yang digunakan adalah DEBU (Demonstrasi, Bahas, dan Unjuk Kerja). Berdasarkan pelatihan ini maka kesimpulan yang diperoleh antara lain 1) pelatihan ini mampu meningkatkan kemampuan guru fisika merangkai sumber tegangan listrik berupa power supply untuk mengoperasikan rangkaian listrik yang sudah jadi maupun untuk memeriksa komponen listrik, 2) pelatihan ini mampu meningkatkan kemampuan guru fisika dalam melakukan pengukuran menggunakan alat-alat ukur listrik khususnya menggunakan multimeter baik pada listrik searah (DC) dan listrik bolak balik (AC).
\end{abstract}

Kata kunci: pelatihan, DEBU, guru, fisika, batukliang.

\begin{abstract}
This service about training assembles electrical circuit components with the method of "DEBU" (Demonstration, Discussion and Performance) for physics teachers in Aik Dareq Village, Batukliang District, Central Lombok in 2019. The goal to be achieved in this activity are 1) to increase the ability of physics teachers to assemble electrical voltage sources in the form of power supply to operate ready electrical circuits as well as to examine electrical components, 2) improve the ability of physics teachers to make measurements using electrical measuring instruments in particular using a multimeter both in direct current (DC) and alternating current (AC). This training was conducted at the IPA Laboratory Aliyah Darussalimin NW Madrasah Sengkol Village, Batukliang District, Central Lombok. The targets of this activity include 1) Madrasah Aliyah physics teacher in Aik Dareq Village, Batukliang District, 2) Madrasah Tsanawiyah physics teacher in Aik Dareq Village, Batukliang District. The methods used are DEBU (Demonstrations, Discussions, and Performance). Based on this training, the conclusions obtained include 1) this training is able to improve the ability of physics teachers to assemble electrical voltage sources in the form of power supply to operate ready electrical circuits as well as check electrical components, 2) this training is able to improve the ability of physics teachers to take measurements using electrical measuring instruments specifically using multimeters both in direct current (DC) and alternating current (AC).
\end{abstract}

Keywords: training,DEBU, teacher, physics, batukliang. 


\section{PENDAHULUAN \\ Analisis Situasi}

Berdasarkan hasil pengamatan langsung ke beberapa sekolah Madrasah Aliyah khususnya di Kecamatan Batukliang, laboratorium IPA masih banyak yang berdebu baik ruangan maupun alat dan bahannya. Berdebunya laboratorium IPA tersebut karena sangat jarang digunakan oleh guru dan siswa dalam melakukan praktikum. Beberapa guru yang kami tanya terkait kenapa laboratorium tersebut berdebu karena laboratorium tidak pernah dimasuki baik oleh guru dan siswa. Selain itu, laboratorium IPA juga jarang sekali dibersihkan.

Sebagaimana penjelasan yang diberikan oleh salah satu guru fisika di MA dan MTs NW Darussalimin Sengkol, Mantang mengatakan bahwa laboratorium IPA hanya difungsikan saat adanya kegiatan akreditasi sekolah. Alat dan bahan di dalam laboratorium sekolah tersebut termasuk cukup lengkap baik untuk pelajaran fisika, biologi, dan kimia. Namun penggunaan laboratorium sebagai media mempraktikkan ilmu IPA khususnya fisika tidak sebanding dengan lengkapnya alat dan bahan tersebut. Berdasarkan hasil wawancara langsung dengan guru fisika di sekolah tersebut mengatakan bahwa guru fisika tersebut belum menguasai dalam merangkai komponen atau alat dan bahan di dalam laboratorium menjadi sebuah media pembelajaran di kelas. Alat yang masih sulit dirangkai menurut mereka adalah komponen atau alat-alat listrik. Berdasarkan hasil observasi langsung antara kami dan guru fisika di sana, alat-alat listrik yang dimiliki di laboratorium termasuk lengkap. Penyebab utama mereka kesulitan merangkai alat-alat listrik tersebut karena guru fisika sudah lupa karena saat kuliah S1 dulu jarang melakukan praktik. Selain itu, guru fisika masih memiliki motivasi yang rendah untuk mencoba sendiri dalam merangkai alat. Hal ini memberikan dampak yang kurang baik bagi pembelajaran. Dampak kurang baik tersebut adalah pembelajaran fisika hanya menggunakan metode ceramah saja akibatnya pengalaman siswa dalam pembelaran fisika menjadi sangat kurang.

Guru fisika di MA dan MTs Darussalimin NW itu juga mengatakan sering berkomunikasi dengan rekan-rekan guru fisika di mataram agar mereka bisa membantu merangkai alat listrik terssebut. Namun hasil kesepakatan mereka sering menemukan kendala akibat kesibukan masing-masing guru. Selain itu, pihak masingmasing sekolah juga tidak mau memfasilitasi keinginan mereka akibatnya rencana yang sangat baik tersebut menjadi tidak bisa terlaksana sampai sekarang ini.

\section{Metode Pelaksanaan}

Berdasarkan kesepakatan antara tim pengusul dengan mitra maka pelaksanan kegiatan pengabdian ini akan dilakukan dengan beberapa tahap yaitu tahap 1: persiapan, tahap 2: pelaksaanaan, dan tahap 3: penutup.

1. Tahap 1: Persiapan.

Adapun tahap persiapan ini antara lain:

a. Melakukan koordinasi antara tim pengusul dan sekolah mitra.

b. Melakukan sosialisasi ke sekolah mitra.

c. Menyiapkan modul pelatihan.

d. Menyiapkan waktu dan lokasi pelatihan.

e. Menyiapkan alat dan bahan pelatihan.

f. Menyiapkan jumlah peserta pelatihan.

2. Tahap 2: Pelaksanaan.

Adapun pelaksanaan pelatihan akan dilakukan dengan menerapkan metode DEBU (Demonstrasi, Bahas, dan Unjuk Kerja).

\section{Demonstrasi.}

a. Tim pengusul yang terdiri dari dosen fisika dengan dibantu mahasiswa akan mendemonstrasikan cara merangkai sumber tegangan listrik berupa power supply untuk mengoperasikan rangkaian listrik yang sudah jadi maupun untuk memeriksa komponen listrik.

b. Tim pengusul yang terdiri dari dosen fisika dengan dibantu mahasiswa akan mendemonstrasikan melakukan pengukuran menggunakan alat-alat ukur listrik khususnya menggunakan multimeter baik pada listrik searah (DC) dan listrik bolak balik (AC).

Bahas.

a. Tim pengusul yang terdiri dari dosen fisika dengan mitra akan membahas cara merangkai sumber tegangan listrik berupa power supply untuk mengoperasikan rangkaian listrik yang sudah jadi maupun untuk memeriksa komponen listrik.

b. Tim pengusul yang terdiri dari dosen fisika dengan mitra akan membahas cara melakukan pengukuran menggunakan alatalat ukur listrik khususnya menggunakan multimeter baik pada listrik searah (DC) dan listrik bolak balik (AC).

\section{Unjuk Kerja.}

a. Mitra (guru fisika) dengan didampingi tim pengusul merangkai sumber tegangan listrik berupa power supply untuk mengoperasikan rangkaian listrik yang sudah jadi maupun untuk memeriksa komponen listrik.

b. Mitra (guru fisika) dengan didampingi tim pengusul melakukan pengukuran menggunakan alat-alat ukur listrik khususnya menggunakan multimeter baik pada listrik searah (DC) dan listrik bolak balik (AC).

3. Tahap 3: Penutup.

a. Tim pengusul memeriksa hasil kerja mitra merangkai komponen listrik. 
b. Tim pengusul bersama mitra tetap saling koordinasi dengan mitra terutama melalui WA atau facebook dalam melaksanakan monitoring dan evaluasi terhadap kegiatan pelatihan yang dilakukan.

\section{HASIL DAN PEMBAHASAN Waktu Efektif Pelaksanaan Kegiatan}

Pelatihan ini efektif terlaksana selama 1 hari penuh yakni hari Jumat, 22 Februari 2019. Adapun jadwal kegiatan pelatihan pemasangan saklar listrik sebagai berikut:

Tabel 1.Jenis kegiatan dan pelaksana.

\begin{tabular}{|l|l|l|}
\hline NO & Jenis kegiatan & Pelaksana \\
\hline 1 & $\begin{array}{l}\text { Pendaftaran } \\
\text { peserta pelatihan }\end{array}$ & $\begin{array}{l}\text { Mahasiswa } \\
\text { Fisika/team }\end{array}$ \\
\hline 2 & Pembukaan & $\begin{array}{l}\text { Islahudin, } \\
\text { S.Pd.,M.Pfis }\end{array}$ \\
\hline 3 & $\begin{array}{l}\text { Membuat rangkaian } \\
\text { Seri paralel }\end{array}$ & $\begin{array}{l}\text { Johri sabaryati, } \\
\text { S.Pd.,M.Pfis dan } \\
\text { team }\end{array}$ \\
\hline 4 & $\begin{array}{l}\text { Membuat rangkaian } \\
\text { percobaan Trafo }\end{array}$ & $\begin{array}{l}\text { Islahudin, } \\
\text { S.Pd.,M.Pfis dan } \\
\text { team }\end{array}$ \\
\hline 5 & ISHOMA & - \\
\hline 6 & $\begin{array}{l}\text { Merangkai } \\
\text { komponen ticker } \\
\text { timer untuk Gerak } \\
\text { Lurus Beraturan } \\
\text { (GLB) dan GLBB }\end{array}$ & $\begin{array}{l}\text { Islahudin, } \\
\text { S.Pd.,M.Pfis dan } \\
\text { team }\end{array}$ \\
\hline 7 & Kerja mandiri & Peserta \\
\hline 8 & Penutupan & $\begin{array}{l}\text { Islahudin, } \\
\text { S.Pd.,M.Pfis }\end{array}$ \\
\hline
\end{tabular}

Beberapa dokumen hasil pengbdian tampak pada Gambar 1a, 1b, dan 1c.

\section{Kontribusi Mitra dalam Kegiatan}

Keberhasilan pelaksanaan pelatihan ini sangat ditentukan oleh dukungan dari beberapa pihak terutama Universitas Muhammadiyah Mataram melalui Lembaga Penelitian dan Pengabdian kepada Masyarakat yang telah memberikan dana. Dana yang diberikan sangat membantu tim pengabdian untuk mempersiapkan segala keperluan yang digunakan pada pelatihan ini.

Dukungan sangat penting yang juga sangat menentukan keberhasilan pelatihan ini tidak terlepas dari pihak sekolah MA Darussaalimin NW Sengkol terutama Kepala sekolah dan dewan guru yang telah menyediakan tempat pelatihan dan mitra komunikasi baik sebelum pelatihan maupun selama proses pelatihan.

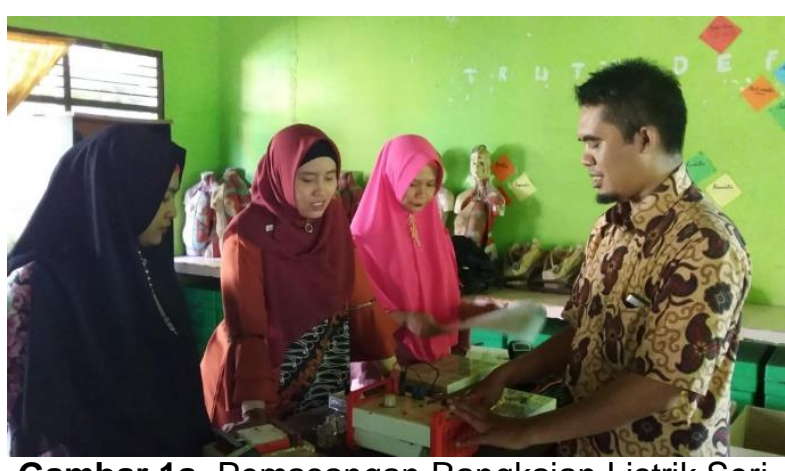

Gambar 1a. Pemasangan Rangkaian Listrik Seri dan Paralel

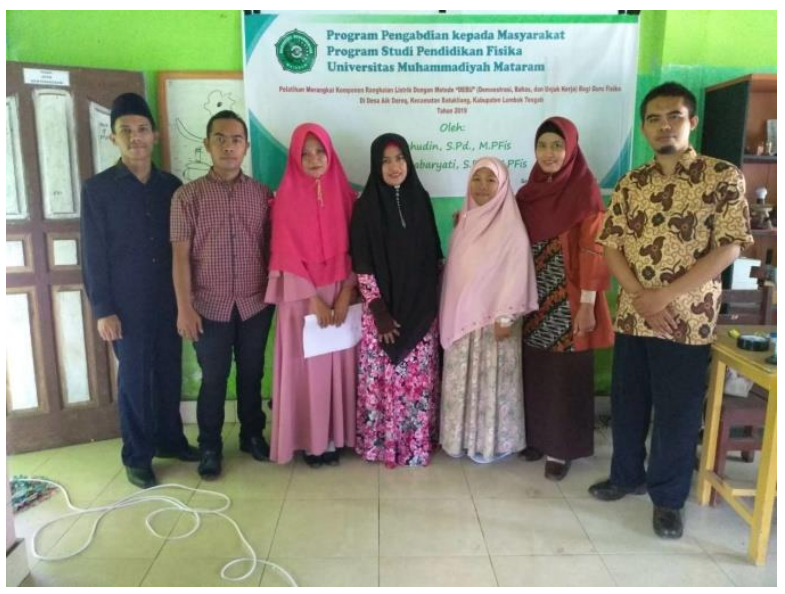

Gambar 1b. Foto Bersama dengan Peserta

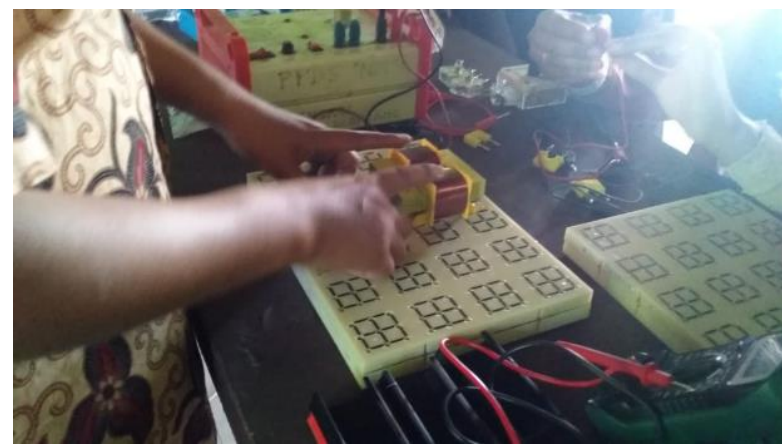

Gambar 1c. Percobaan Trafo

\section{Potret Permasalahan Lain yang Terekam}

Pelatihan ini berjalan dengan lancar tanpa hambatan yang cukup berarti. Antusiasme peserta untuk mengikuti pelatihan ini sangat besar. Guru fisika/IPA sebagai peserta yang ikut dalam pelatihan ini berasal dari 3 sekolah baik MTs dan MA, antara lain MA Darussalimin NW Sengkol, MTs Darussalimin NW Sengkol, MTs NW Tempo, MTs Aziziah Kapek Gunung Sari. Hal ini terlihat dengan para peserta yang lengkap kehadirannya mulai dari acara pembukaan sampai penutupan pelatihan. Namun ada beberapa masalah yang ditemukan selama proses pelatihan ini, antara lain:

1. Mitra/peserta belum mahir menyusun rangkaian pada papan rangkaian sehingga 
harus tetap didampingi oleh dosen Program Studi Pendidikan Fisika UM Mataram.

2. Peserta pelatihan belum familiar menggunakan komponen percobaan Ticker Timer karena belum pernah dicoba di dalam laboratorium.

3. Peserta yang ikut dalam pelatihan ini sebagian besar mengalami kesulitan dalam memasang rangkaian khususnya pada trafo, karena mereka sangat jarang memegang alat-alat listrik tersebut sehingga proses pelatihan membutuhkan penjelasan yang detail.

\section{SIMPULAN DAN SARAN Simpulan}

Berdasarkan pelatihan ini maka kesimpulan yang diperoleh antara lain:

1. Pelatihan ini meningkatkan kemampuan guru fisika merangkai sumber tegangan listrik berupa power supply untuk mengoperasikan rangkaian listrik yang sudah jadi maupun untuk memeriksa komponen listrik.

2. Pelatihan ini mampu meningkatkan kemampuan guru fisika dalam melakukan pengukuran menggunakan alat-alat ukur listrik khususnya menggunakan multimeter baik pada listrik searah (DC) dan listrik bolak balik (AC).

\section{Saran}

Adapun saran yang dapat dikemukakan berdasarkan pelatihan ini antara lain:

1. Perlu ada pelatihan secara berkelanjutan agar program EWB bisa dipahami secara mendalam.

2. Pemasangan lampu listrik bersaklar di rumah tangga menggunakan konsep EWB (Electronics Workbench) perlu diaplikasikan secara langsung oleh para peserta terutama sekali ketika peserta ingin memperbaiki sendiri instalasi listrik di dalam rumahnya.

\section{DAFTAR RUJUKAN}

Islahudin, I., Isnaini, M, (2019). Pemanfaatan Laboratorium Virtual Berbasis Software Electronics Workbench (EWB) Untuk Menunjang Pemahaman Konsep Mahasiswa Pada Mata Kuliah Elektronika Dasar I, ORBITA : Jurnal Kajian, Inovasi, dan Aplikasi Pendidikan Fisika, 5(2), 96100

Islahudin, I., \& Sabaryati, J. (2018). PELATIHAN PEMASANGAN LAMPU LISTRIK BERSAKLAR DI RUMAH TANGGA MENGGUNAKAN KONSEP EWB (ELECTRONICS WORKBENCH) BAGI SISWA SMKN I BATU KLIANG UTARA DESA AIK BERIQ KECAMATAN BATU KLIANG UTARA KABUPATEN LOMBOK TENGAH TAHUN 2017. SELAPARANG Jurnal Pengabdian Masyarakat Berkemajuan, 1(2), 5-8.
Islahudin, I., Khaerani, S., \& Zulkarnain, Z. (2018). Pemanfaatan Laboratorium Virtual Berbasis Ewb (Electronics Workbench) Terhadap Peningkatan Hasil Belajar Fisika Siswa IPA Kelas XII IPA Ma NW Darussalimin Sengkol, Batukliang Lombok Tengah Tahun Pelajaran 2018/2019. ORBITA: Jurnal Kajian, Inovasi dan Aplikasi Pendidikan Fisika, 4(2), 47-51.

Islahudin, I., \& Fatimah, N. (2018). RANCANG BANGUN SENSOR GETARAN BERBASIS KOIL DATAR UNTUK MENGANALISIS DAYA REDAM VIBRASI BEBERAPA JENIS KAYU TIDAK AWET UNTUK BANGUNAN RUMAH SEDERHANA. ORBITA: Jurnal Kajian, Inovasi dan Aplikasi Pendidikan Fisika, 4(1), 21-27.

Fatimah, N., Islahudin, I., \& Sabaryati, J. (2018). SENSOR ELASTISITAS BERBASIS KOIL DATAR UNTUK MENGHITUNG KONSTANTA ELASTISITAS BEBERAPA JENIS KAYU TIDAK AWET UNTUK BANGUNANRUMAH SEDERHANA. ORBITA: Jurnal Kajian, Inovasi dan Aplikasi Pendidikan Fisika, 4(1), 1-7. 